\title{
Molecular characterization of Vibrio cholerae 01 strains circulating in Assam: a north eastern state of India
}

\author{
Ajanta Sharma ${ }^{1 *}$, Bornali Sarmah Dutta ${ }^{1}$, Debajit Rabha ${ }^{1}$, Elmy Samsun Rasul ${ }^{2}$, Naba Kumar \\ Hazarika $^{1}$ \\ ${ }^{1}$ Department of Microbiology, Gauhati Medical College, Guwahati, Assam \\ ${ }^{2}$ Department of Microbiology, Fakaruddin Ali Ahmed Medical College, Barpeta, Assam
}

Received: December 2020, Accepted: August 2021

\begin{abstract}
Background and Objectives: Information on the genetic epidemiology of cholera in Assam, a northeastern state of India is lacking despite cholera being a major public health problem. The study aimed to determine the virulence genes and genes encoding antibiotic resistance in Vibrio cholerae isolates and to determine the prevalent genotypes based on the presence or absence of the virulence genes and $\operatorname{ctx} B$ genotype.

Materials and Methods: Twenty-five $V$. cholerae strains were subjected to conventional biotyping and serotyping followed by multiplex PCR to detect $c t x A, c t x B$, zot, ace, Olrfb, tcpA, ompU, ompW, rtxC, hly and toxR and antibiotic resistance genes. Cholera toxin B $(c t x B)$ gene was amplified followed by sequencing.

Results: All the $V$. cholerae $\mathrm{O} 1$ isolates were El Tor Ogawa and showed the presence of the core toxin region representing the genome of the filamentous bacteriophage CTX $\varnothing$. The complete cassette of virulence genes was seen in $48 \%$ of the isolates which was the predominant genotype. All the isolates possessed amino acid sequences identical to the El Tor $c t x B$ subunit of genotype 3. sulII gene was detected in $68 \%$ of the isolates, $d f r A 1$ in $88 \%$, strB in $48 \%$ and $S X T$ gene was detected in $36 \%$ of the isolates.

Conclusion: Toxigenic $V$. cholerae O1 El Tor Ogawa strains of $c t x B$ genotype 3 carrying a large pool of virulence genes are prevailing in Assam. Presence of a transmissible genetic element SXT in 36\% of the strains is of major concern as it indicates the emergence of multiple drug resistance among the V. cholerae isolates.
\end{abstract}

Keywords: Vibrio cholerae O1; Cholera toxin; Virulence; Genotype; Drug resistance

\section{INTRODUCTION}

Cholera still remains a global threat to public health in the developing countries where access to safe water and adequate sanitation cannot be assured for all. There are 2.9 million cases of cholera with 95,000 deaths occurring annually in endemic countries between 2008-2012. India is a country with more than 100,000 cases occurring annually (1). However, the actual global burden of cholera is not known as the vast majority of cases are not reported. WHO estimates that only $5-10 \%$ of the cases occurring annually are officially reported (2).

The causative agent of cholera, Vibrio cholerae is antigenically diverse organism and based on antigenic diversity of their outer membrane lipopolysaccharides, 206 serogroups (O1-O206) have been identified $(3,4)$. $V$. cholerae serogroup $\mathrm{O} 1$ is further classified into two biotypes, classical and El Tor, and two major serotypes, Ogawa and Inaba (5). Global

*Corresponding author: Ajanta Sharma, Ph.D, Department of Microbiology, Gauhati Medical College, Guwahati, Assam. Tel: +91-9435011302 Fax: +91-361-2529457 Email: ajantasharma2002@yahoo.com 
replacement of $V$. cholerae classical biotype by $\mathrm{El}$ Tor biotype, emergence of $\mathrm{O} 139$ serogroup and rapid spread of antibiotic resistant strains indicate the continuous evolution in $V$. cholerae. The altered variant of El Tor strains containing the classical type of $\operatorname{ctx} B$ currently dominates globally.

Pathogenesis of $V$. cholerae is a complex process that involves coordinated expression of several virulence-associated genes to cause disease. The complete virulence profile of $V$. cholerae, including direct and indirect expression of genes involved in its survival and stress adaptation in the host are yet to be fully explored. The two major virulence factors that are associated with the generation of the symptoms of cholera are the cholera toxin (CT) responsible for the production of profuse rice-watery diarrhea and the toxin-coregulated pilus ( $t c p$ ), a type IV pilus that mediates adherence, microcolony formation and intestinal colonization (6). Interestingly, the production of these virulence factors (CT and tcp) is strongly influenced by environmental conditions. Cholera toxin (CT), and toxin co-regulated pilus (TCP) are part of the genome of two horizontally acquired Mobile Genetic Elements (MGEs), СTXФ, and Vibrio pathogenicity island 1 (VPI-1), respectively (7). Apart from CT, the pathogenesis of cholera also relies on the synergistic action of a number of other genes like tcp, ace (accessory cholera enterotoxin), zot (zonula occludens toxin) and tox $R$ the regulatory gene for CT production. Furthermore, the hemolysin of $V$. cholerae (hly), is extracellular membrane damaging proteins plays important role in manifestation of cholera (8). ompW is the species-specific gene and $r f b O 1$ genes confirm $\mathrm{O} 1$ serogroup of the isolates (9).

Emergence of new strains in any species of bacterial population have always been challenging. $V$. cholerae being no different from other bacteria, persists around the globe and undergo evolution over time. Its dual characteristic feature of being able to be sustained in the environmental (less infectious) and infectious state, and changing or acquiring various virulence genes or mobile genetic elements makes it difficult to understand the pathogenesis of $V$. cholerae. Increased poverty, overall reduction in water quality, excessive misuse of antibiotics and climatic changes are encouraging further genetic exchange of virulence and antibiotic resistance (6).

Assam is a state which is fed by the very dynamic and unstable river Brahmaputra and its tributaries causing frequent floods during monsoon due to incessant rainfall. Increased rainfall is associated with increased risk of cholera because during the flood, sewage water contaminates surface and groundwater that individuals rely on for drinking, bathing, and washing clothes which is a natural fauna of cholera in Assam. Apart from that, earlier studies have reported that the spatiotemporal serotype shifts and genetic diversity of $V$. cholerae strains between epidemics and pandemics may be due to climatic variations influencing the switching of virulence factors (10-12). Globally, increased cases of dynamic $V$. cholerae strains, their serological switching and disease occurrence with respect to climate change (warm climate- more, cool climate- less) have attracted the attention of the public health sector (13).

Also, Assam is a state with highly diverse population in terms of ethnicity, religion and language. Of the 220 separate ethnic groups of North east India (NER), more than 30 of them are in Assam, which has over $70 \%$ of the North east region's population. There has been a consistent flow of migration in this region because of employment opportunities in tea gardens, availability of cultivable land and other related factors. Assam also has interlinked borders with other states of NER as well as other countries like Bhutan and Bangladesh and may have different genotypic divergence in their virulence profile and antibiotic resistance pattern, the study of which may help to formulate the prevention and control strategy of cholera in the state.

To the best of our knowledge, no published literature has been found describing the virulence and antibiotic resistance gene profile of $V$. cholerae in Assam. As per Integrated Disease Surveillance project (IDSP) data, 48 outbreaks of cholera have been reported from various districts of Assam during the period 2012 to 2015 . No data related to the molecular characterization of the isolates from these outbreaks have been published so far. The emergence of antimicrobial resistance is also a global phenomenon. Multiple drug-resistant $V$. cholerae strains was reported from this region earlier also (14).

In this context, the present study was undertaken to characterize the $V$. cholerae strains based on distribution of virulence associated genes and antibiotic resistance genes among $V$. cholerae strains in Assam and to compare the virulence profile of the strains with that of the strains circulating in other regions of India. 


\section{MATERIALS AND METHODS}

Study design. The study was carried out after obtaining approval from the Institutional Ethics Committee. Acute watery diarrhea (AWD) cases referred to the hospital from various districts of Assam were included in the study after taking written consent. Twenty-five Vibrio cholerae O1 strains El Tor isolated by standard bacteriological methods during a period of two and half years were included in the study (15, 16). For further confirmation, serotyping was done using antisera obtained from DENKA, SEIKEN CO LIMITED, Tokyo, Japan.

Multiplex PCR for detection of biotypes and virulence genes of $\boldsymbol{V}$. cholera. $V$. cholerae strains were subcultured on Luria-Bertani agar, suspended in sterile deionized water to a turbidity of $2.0 \mathrm{Mc}$ Farland standard and then boiled for 10 minutes. Two sets of multiplex PCR assay were performed to detect the presence of diverse gene traits. The first multiplex PCR detected tcp A (El Tor), ctxA, Olrfb, rtxC, ompU, hlyA, zot, and ompW genes. The second set of multiplex PCR detected tcpA (Classical), ace, toxR genes. The primers are listed in Table $1(9,17-21)$.

The reaction mixture consisted of dNTPs (200 $\mu \mathrm{M}), \mathrm{MgCl}_{2}(1.5 \mathrm{mM})$, Taq polymerase (1U), primers specific for target gene ( $2 \mu 1$ each), template DNA (100 ng), and milli-Q water. The thermal cycling condition for both the multiplex PCR was pre-incubation at $94^{\circ} \mathrm{C}$ for $2 \mathrm{~min}$ followed by denaturation for $1 \mathrm{~min}$ at $94^{\circ} \mathrm{C}$, annealing for $1 \mathrm{~min}$ at $59^{\circ} \mathrm{C}$, extension for 2 min at $72^{\circ} \mathrm{C}$ and incubation at $72^{\circ} \mathrm{C}$ for $10 \mathrm{~min}$ for a final extension.

After the completion of 30 cycles of reactions, 10 $\mu \mathrm{l}$ of each of the PCR products were mixed individually with $2 \mu$ l of gel loading buffer. Electrophoresis was done on $2 \%$ agarose along with $100 \mathrm{bp}$ ladder as a molecular marker and stained with $0.5 \mathrm{Mg} / \mathrm{ml}$ of ethidium bromide and the bands were observed using a UV transilluminator (Fig. 1A and B). Genotyping was done based on the presence or absence of the virulence genes (Table 2).

Multiplex PCR procedure was standardized using reference strains of Gastrointestinal Tract Pathogen Repository (GTPR) work V. cholerae O1 Ogawa (GTPR ID 413), $V$. cholerae O1 Inaba (GTPR ID 842), V. cholerae O139 (GTPR ID 1144), V. cholerae classical (MTCC 3904) and V. cholerae O139 (MTCC 3906) obtained from National Institute of
Cholera and Enteric Diseases (NICED), Kolkata and Microbial Type Culture Collection, Institute of Microbial Technology, Chandigarh, India (MTCC) respectively.

Multiplex PCR for detection of antibiotic resistance genes of $V$. cholerae 01 . Another Multiplex PCR assay was performed to detect antibiotic resistance genes for sullI (encoding sulfamethoxazole resistance), dfrAl (O1-specific trimethoprim resistance), strB (Streptomycin B resistance), SXT (novel transmissible genetic element which contains the genes encoding resistance to these antibiotics), $d$ fr 18 (O139-specific trimethoprim resistance) (Fig. 1B). The primers are listed in Table 1 (22-25).

Sequencing of $\boldsymbol{c t x} \boldsymbol{B}$ gene. To determine the genotype of cholera toxin, Cholera toxin $\mathrm{B}(\operatorname{ct} x B)$ gene was amplified from the isolates using the $\operatorname{ct} x B$ F GCCGGGTTGTGGGAATGCTCCAAG and $c t x B$ R CATGCGATTGCCGCAATTAGTATGGC primers as described earlier (17). Purification of amplified product was performed by Exonuclease I-SAP (Shrimp Alkaline phosphatase) from Thermo Scientific, USA. Eluate was used as a purified gene product for sequencing which was performed for both the strands using the above-mentioned primers and BigDye ${ }^{\circledR}$ Terminator Cycle Sequencing Kit, Version 3.1 (Applied Biosyste$\mathrm{ms}$, Foster City, USA). The sequencing reactions were analyzed on ABI 3500 Genetic Analyzer (Applied Bio systems ${ }^{\circledR}$ Foster City, USA). The consensus sequences were prepared using BioEdit sequence alignment editor (version 7.2.5) and searched against the GenBank database of the National Center for Biotechnology Information (NCBI) using the BLASTN algorithm (http://blast.ncbi.nlm.nih.gov/). The sequences obtained here were deposited in GenBank and the accession numbers are MK016537, MK016538, MK016539, MK029003, MK029004, MK29005.

\section{RESULTS}

All the strains tested were positive for the species-specific gene ompW and serogroup- specific $O 1 r f b$, thus confirming that all the isolates were $V$. cholerae O1. Detection of biotype-specific tcpA gene and $r t x C$ gene revealed that, all the isolates belonged to biotype El Tor. Serotyping revealed that, all the isolates belonged to serotype Ogawa. 


\section{AJANTA SHARMA ET AL.}

Table 1. List of primers used for detection of biotypes, virulence, and antibiotic resistance genes

\begin{tabular}{|c|c|c|c|c|}
\hline Serial No. & Target & Nucleotide sequence $\left(5^{\prime} \rightarrow 3^{\prime}\right)$ & $\begin{array}{l}\text { Amplicon } \\
\text { Size (bp) }\end{array}$ & Reference \\
\hline \multicolumn{5}{|c|}{ First set of PCR primers } \\
\hline \multirow[t]{2}{*}{1} & tcp A (F), El Tor & GAAGAAGTTTGTAAAAGAAGAACAC & 472 & Keasler \& Hall (1993) (18) \\
\hline & tcp $A(\mathrm{R}), \mathrm{El}$ Tor & GAAGGACCTTCTTTCACGTTG & & \\
\hline \multirow[t]{2}{*}{2} & ompU $(\mathrm{F})$ & CCAAAGCGGTGACAAAGC & 655 & Kumar et al. (2009) (19) \\
\hline & $o m p U(\mathrm{R})$ & TTCCATGCGGTAAGAAGC & & \\
\hline \multirow[t]{2}{*}{3} & $r f b O 1(\mathrm{~F})$ & TCTATGTGCTGCGATTGGTG & 638 & Goel et al. (2007) (17) \\
\hline & $r f b O 1(\mathrm{R})$ & CCCCGAAAACCTAATGTGAG & & \\
\hline \multirow[t]{2}{*}{4} & $r t x C(\mathrm{~F})$ & CGACGAAGATCATTGACGAC & 265 & Chow et al. (2001) (20) \\
\hline & $\operatorname{rtx} C(\mathrm{R})$ & CATCGTCGTTATGTGGTTGC & & \\
\hline \multirow[t]{2}{*}{5} & $\operatorname{ctx} A(\mathrm{~F})$ & CTCAGACGGGATTTGTTAGGCACG & 301 & Keasler \& Hall (1993) (18) \\
\hline & $\operatorname{ctx} A(\mathrm{R})$ & TCTATCTCTGTAGCCCCTATTACG & & \\
\hline \multirow[t]{2}{*}{6} & $z o t(\mathrm{~F})$ & TCGCTTAACGATGGCGCGTTTT & 947 & Singh et al. (2001) (21) \\
\hline & zot $(\mathrm{R})$ & AACCCCGTTTCACTTCTACCCA & & \\
\hline \multirow[t]{2}{*}{7} & hlyA (F) & GAGCCGGCATTCATCTGAAT & 480 & Kumar et al. (2009) (19) \\
\hline & $h l y A(\mathrm{R})$ & CTCAGCGGGCTAATACGGTTTA & & \\
\hline \multirow[t]{2}{*}{8} & ompW $(\mathrm{F})$ & CACCAAGAAGGTGACTTTATTGTG & 304 & Nandi et al. (2000) (9) \\
\hline & ompW $(\mathrm{R})$ & GGTTTGTCGAATTAGCTTCACC & & \\
\hline \multicolumn{5}{|c|}{ Second set of PCR primers } \\
\hline \multirow[t]{2}{*}{9} & tcp A (F), Classical & CACGATAAGAAAACCGGTCAAGAG & 618 & Keasler \& Hall (1993) (18) \\
\hline & tcp A (R), Classical & ACCAAATGCAACGCCGAATGGAGC & & \\
\hline \multirow[t]{2}{*}{10} & $\operatorname{ctx} B(\mathrm{~F})$ & GCCGGGTTGTGGGAATGCTCCAAG & 536 & Goel et al. (2007) (17) \\
\hline & $\operatorname{ctx} B(\mathrm{R})$ & CATGCGATTGCCGCAATTAGTATGGC & & \\
\hline \multirow[t]{2}{*}{11} & $\operatorname{ace}(\mathrm{F})$ & TAAGGATGTGCTTATGATGGACACCC & 309 & Kumar et al. (2009) (19) \\
\hline & $\operatorname{ace}(\mathrm{R})$ & CGTGATGAATAAAGATACTCATAGG & & \\
\hline \multirow[t]{2}{*}{12} & $\operatorname{tox} R(\mathrm{~F})$ & CCTTCGATCCCCTAAGCAATAC & 779 & Singh et al. (2001) (21) \\
\hline & $\operatorname{tox} R(\mathrm{R})$ & AGGGTTAGCAACGATGCGTAAG & & \\
\hline \multicolumn{5}{|c|}{ Primers used for detection of antibiotic resistance genes } \\
\hline \multirow[t]{2}{*}{1} & SulII (F) & TGTGCGGATGAAGTCAGCTCC & 626 & Hochhut et al. (2001) (22) \\
\hline & $\operatorname{SulII}(\mathrm{R})$ & AGGGGGCAGATGTGATCGAC & & \\
\hline \multirow[t]{2}{*}{2} & $d f r A l(\mathrm{~F})$ & CAAGTTTACATCTGACAATGAGAACGTAT & 278 & Falbo et al. (1999) (23) \\
\hline & $d f r A 1(\mathrm{R})$ & ACCCTTTTGCCAGATTTGGTA & & \\
\hline \multirow[t]{2}{*}{3} & $\operatorname{str} B(\mathrm{~F})$ & CCGCGATAGCTAGATCGCGTT & 515 & Ramachandran et al. (2007) (24) \\
\hline & $\operatorname{str} B(\mathrm{R})$ & CGACTACCAGGCGACCGAAAT & & \\
\hline \multirow[t]{2}{*}{4} & $S X T(\mathrm{~F})$ & ATGGCGTTATCAGTTAGCTGGC & 1035 & Bhanumathi et al. (2003) (25) \\
\hline & $S X T(\mathrm{R})$ & GCGAAGATCATGCATAGACC & & \\
\hline \multirow[t]{2}{*}{5} & $d f r 18(F)$ & ACTGCCGTTTTCGATAATGTGG & 389 & Hochhut et al. (2001) (22) \\
\hline & $D f r 18(\mathrm{R})$ & GGGTAAGACACTCGTCATGGG & & \\
\hline
\end{tabular}

Among the virulence genes, $c t x A$ gene was present in $88 \%$, ompU in $64 \%$, zot in $64 \%$, hlyA in $84 \%$, ace in $92 \%$ and toxR in $100 \%$ of the isolates. Based on the virulence genes analyzed, five genotypes of $V$. cholerae $\mathrm{O} 1$ were identified. Genotyping revealed, genotype tcpA $(E l)+c t x A+o m p U+r t x C+o m p W+$ $z o t+O \operatorname{lrfb}+h l y A+c t x B+a c e+t o x R+$ i.e. complete cassette of virulence genes was identified in $48 \%$ of the $V$. cholerae strains and was the most predominant genotype (Table 2).

Detection of antibiotic resistance genes. sulII was detected in $68 \%$ indicating resistance to sulphamethoxazole, strB in $48 \%$ indicating streptomycin B 


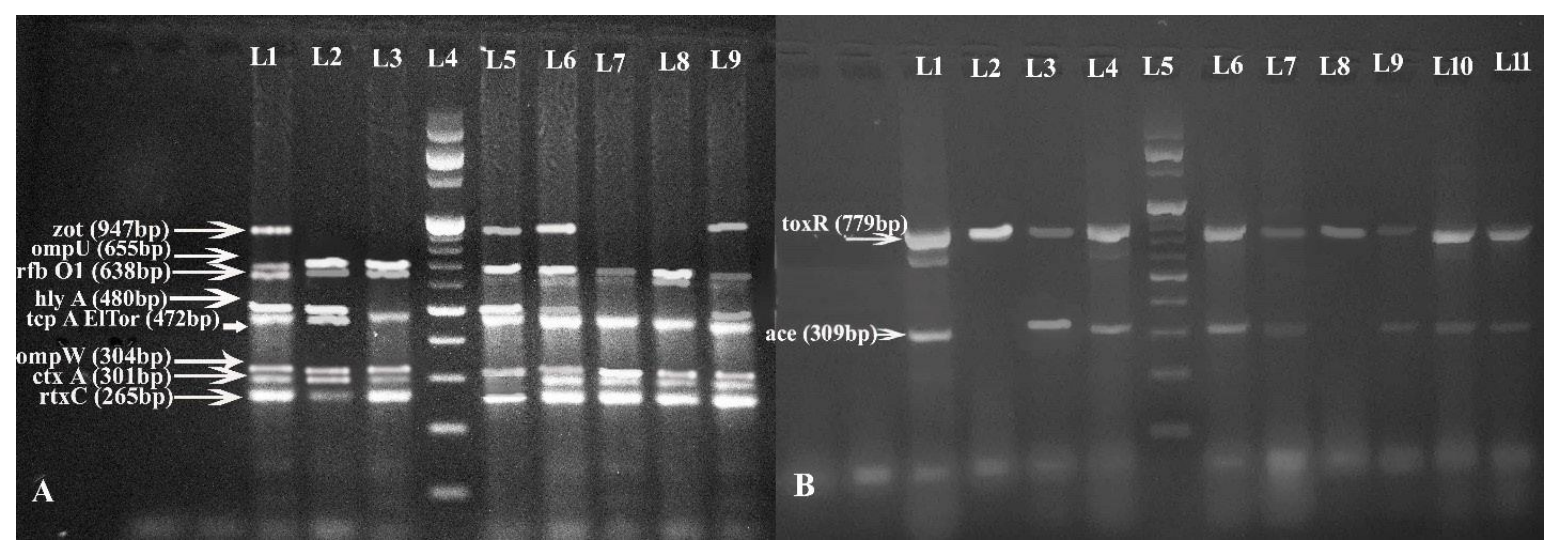

Fig. 1. A-Multiplex PCR 1- Lane 1, 6 \& 9 (Genotype 1) showing complete cassette of virulence genes tcpA El Tor (472 bp), rtxC (265 bp), ompU (655 bp), hly A (480 bp), zot (947 bp); B- ace (309 bp), toxR (779 bp); Lane 2 (Genotype 2): Absence of zot; Lane 3, 7 \& 8 (Genotype 3): Absence of hlyA and zot; Lane 4: 100 bp DNA ladder; Lane 5 (Genotype 4): Absence of ctxA; B-Multiplex PCR 2- Lane 1, 3, 4, 6, 7, 9-11 (Genotype 1): ace (309 bp), tox R (779 bp); Lane 2 \& 8 (Genotype 5): Absence of ace; Lane 5: 100 bp DNA ladder.

Table 2. Representative genotypes of Vibrio cholerae $\mathrm{O} 1$ strains

\begin{tabular}{|c|c|c|}
\hline Straina & District & Genotype \\
\hline 12 & Kamrup Metro and Rural & 1. tcpA $(E l) b+c t x A+o m p U+r t x C+o m p W+z o t+O 1 r f b+h l y A+c t x B+a c e+t o x R+$ \\
\hline 5 & Darrang & 2. tcpA $(E l)+c t x A+o m p U+r t x C+o m p W+z o t-O 1 r f b+h l y A+c t x B+a c e+t o x R+$ \\
\hline 3 & Barpeta & 3. $t c p A(E l)+c t x A+o m p U+r t x C+z o t-o m p W+O 1 r f+h l y A-c t x B+a c e+t o x R+$ \\
\hline 3 & Barpeta \& Nalbari & 4. $t c p A(E l)+c t x A-o m p U+r t x C+o m p W+z o t+O 1 r f b+h l y A+c t x B+a c e+t o x R+$ \\
\hline 2 & Morigaon and Golaghat & 5. $t c p A(E l)+c t x A+o m p U+r t x C+o m p W+z o t+O l r f b+h l y A+c t x B+$ ace - tox $R+$ \\
\hline
\end{tabular}

aData are numbers of strains showing the same genotype

bAbbreviations: El-El Tor

resistance, $d f r A l$ in $88 \%$ indicating trimethoprim resistance. Detection of SXT element in $36 \%$ of the isolates indicates that a considerable proportion of the isolates possess the transmissible genetic element which contains the genes encoding resistance to multiple antibiotics.

Genotyping based on $\operatorname{ct} \boldsymbol{B} \boldsymbol{B}$ gene. The sequences of $\operatorname{ct} x B$ gene of reference strains Vibrio cholerae O1 El Tor N16961 (Accession No. NC_002505) and Vibrio cholerae O1 classical 569B (Accession No. U25679), El Tor, Australia (2463, 1988) were retrieved from GenBank. The deduced amino acid sequences of the $\operatorname{ct} x B$ gene from all strains were aligned using CLUSTAL W.

The deduced amino acid sequence alignment of partial $c t x B$ subunit of $V$. cholerae $\mathrm{O} 1 \mathrm{El}$ Tor isolated in the present study against reference strains revealed that, the isolates of present study possessed amino acid sequences identical to the El Tor type of CT-B subunit, which was $100 \%$ identical to the amino acid sequence of El Tor reference strain N16961 of genotype 3 by having aspartate at position 28, tyrosine at position 39, phenylalanine at position 46 and isoleucine at position 68 (Table 3).

\section{DISCUSSION}

The V. cholerae $\mathrm{O} 1 \mathrm{El}$ Tor isolates of the present study possessed different virulence genes like $\operatorname{ct} x A$, Olrfb, rtxC, ompU, hlyA, zot, ompW, ace, toxR that indicates some toxigenic strain of $V$. cholerae are circulating in Assam. Cholera toxin (CT) is the most important epidemic marker among various toxins produced by $V$. cholerae, which is encoded by a mobile element, the genome of a filamentous CTX bacteriophage (26). Three strains of $V$. cholerae were negative for $c t x A$ after repeated PCR. These findings may suggest that some $V$. cholerae strains can cause 
AJANTA SHARMA ET AL.

Table 3. Genotypes of Vibrio cholerae O1 strains based on the DNA sequence of the ctx B subunit genes

\begin{tabular}{|c|c|c|c|c|c|c|c|c|c|c|c|}
\hline \multirow[t]{2}{*}{ Strain identification } & \multicolumn{5}{|c|}{ Nucleotide at position } & \multicolumn{5}{|c|}{ Amino acid at position } & \multirow[t]{2}{*}{ ctxB genotype } \\
\hline & 83 & 101 & 115 & 138 & 203 & 28 & 34 & 39 & 46 & 68 & \\
\hline Classical 569B & $\mathrm{A}$ & $\mathrm{A}$ & $\mathrm{C}$ & $\mathrm{T}$ & $\mathrm{C}$ & $\mathrm{D}$ & $\mathrm{H}$ & $\mathrm{H}$ & $\mathrm{F}$ & $\mathrm{T}$ & Genotype 1 \\
\hline El Tor, Australia 2463 & A & A & $\mathrm{C}$ & G & $\mathrm{C}$ & $\mathrm{D}$ & $\mathrm{H}$ & $\mathrm{H}$ & $\mathrm{L}$ & $\mathrm{T}$ & Genotype 2 \\
\hline El Tor N16961 & A & A & $\mathrm{T}$ & $\mathrm{T}$ & $\mathrm{T}$ & $\mathrm{D}$ & $\mathrm{H}$ & $\mathrm{Y}$ & $\mathrm{F}$ & I & Genotype 3 \\
\hline MK016537 & A & A & $\mathrm{T}$ & $\mathrm{T}$ & $\mathrm{T}$ & $\mathrm{D}$ & $\mathrm{H}$ & $\mathrm{Y}$ & $\mathrm{F}$ & I & Genotype 3 \\
\hline MK016538 & A & $\mathrm{A}$ & $\mathrm{T}$ & $\mathrm{T}$ & $\mathrm{T}$ & $\mathrm{D}$ & $\mathrm{H}$ & $\mathrm{Y}$ & $\mathrm{F}$ & I & Genotype 3 \\
\hline MK016539 & $\mathrm{A}$ & A & $\mathrm{T}$ & $\mathrm{T}$ & $\mathrm{T}$ & $\mathrm{D}$ & $\mathrm{H}$ & $\mathrm{Y}$ & $\mathrm{F}$ & I & Genotype 3 \\
\hline МK029003 & A & $\mathrm{A}$ & $\mathrm{T}$ & $\mathrm{T}$ & $\mathrm{T}$ & $\mathrm{D}$ & $\mathrm{H}$ & $\mathrm{Y}$ & F & I & Genotype 3 \\
\hline МK029004 & A & $\mathrm{A}$ & $\mathrm{T}$ & $\mathrm{T}$ & $\mathrm{T}$ & $\mathrm{D}$ & $\mathrm{H}$ & $\mathrm{Y}$ & F & I & Genotype 3 \\
\hline MK29005 & A & $\mathrm{A}$ & $\mathrm{T}$ & $\mathrm{T}$ & $\mathrm{T}$ & $\mathrm{D}$ & $\mathrm{H}$ & $\mathrm{Y}$ & $\mathrm{F}$ & I & Genotype 3 \\
\hline
\end{tabular}

illness in the absence of the cholera toxin. The absence of the $\operatorname{ct} x A$ gene may also be due to the $\operatorname{ctx} \varphi$ prophage genome being missing or disrupted by mutations (27). However, the study could not exclude the possibility of strain diversity which probably could not be detected by the primers used in the study. All the $\operatorname{ct} x A$ negative strains were positive for accessory cholera toxin (ace), zonula occludens toxin (zot) and haemolysin A ( hlyA) genes. This finding is similar to Alishahi et al. (2013) and Abana et al. (2019) (27, 28). All isolates were positive for tcpA El Tor which is similar to the findings of Abana et al. (2019) and Zaw et al. (2019) $(27,29)$.

In the present study $8(32 \%)$ isolates possessed the ctx gene without the zot gene as well as $3(8 \%)$ of the isolates possessed zot gene without the ctx gene, which is similar to a study conducted by Akoachere et al. (2014) (30). This may suggest that occurrence of zot gene may be independent of the $c t x$ gene.

The screening for virulence genes revealed five different patterns or genotypes thus revealing the diversity among the strains even though all of them were clinical isolates pertaining to different districts of Assam. The predominant genotype included all the virulence genes investigated in the study. Determination of the genotypes based on the presence or absence of specific virulence genes only through in vitro test may not always indicate the severity of the strain as the expression of them in individuals may vary. However, the analysis of the virulence genes showed that the positive rates for the major virulence genes were mostly seen among the strains from Kamrup rural district which had large outbreak of cholera. A comparison of the virulence gene profile of $V$. cholerae isolates from different regions of India is presented in Table 4.
Sequencing of the partial $\operatorname{ctx} B$ gene revealed that the cholera outbreaks in certain districts of Assam were due to $V$. cholerae $\mathrm{O} 1 \mathrm{El}$ Tor carrying the $\operatorname{ct} x B$ gene of genotype 3. However, Borkakoty et al. (2012) reported circulation of $V$. cholerae $\mathrm{O} 1 \mathrm{El}$ Tor variant carrying the classical ct $x B C$ gene in upper Assam (31). Chatterjee et al. (2009) and Goel et al. (2010) also reported the presence of $V$. cholerae $\mathrm{O} 1 \mathrm{El}$ Tor variant carrying the classical $\operatorname{ct} x B C$ gene in eastern and southern India respectively $(32,33)$.

Multiple antibiotic resistances among $V$. cholerae have emerged as a major problem worldwide. In India, there is a progressively increasing trend of antibiotic resistance towards common antibiotics like tetracycline and fluoroquinolones (14, 34-36). Resistance to these antibiotics could be due to the extensive use of these antibiotics for the treatment of other infectious diseases. The re-emergence of the cholera epidemic and the evolution of multidrug-resistant $V$. cholerae over the last decade, particularly in Asian countries, pose a great threat to the clinical diagnosis and treatment of cholera. The utmost concern is the acquisition of the SXT element by $36 \%$ of the isolates in the study. Similar to other bacteria, the spread of antibiotic resistance in $V$. cholerae is also facilitated by horizontal gene transfer via self-transmissible mobile genetic elements like SXT. Although identifying the serogroup and serotype of $V$. cholerae isolates is not necessary for treatment of cholera, this information may be of epidemiologic and public health importance. However, earlier studies have reported that, multiple drug resistance was more prevalent among the $V$. cholerae $\mathrm{O} 1 \mathrm{El}$ Tor Ogawa serotypes $(31,34)$. Hence, active surveillance is required for continuous monitoring of the serotype shift and emergence of antibiotic resistance. 


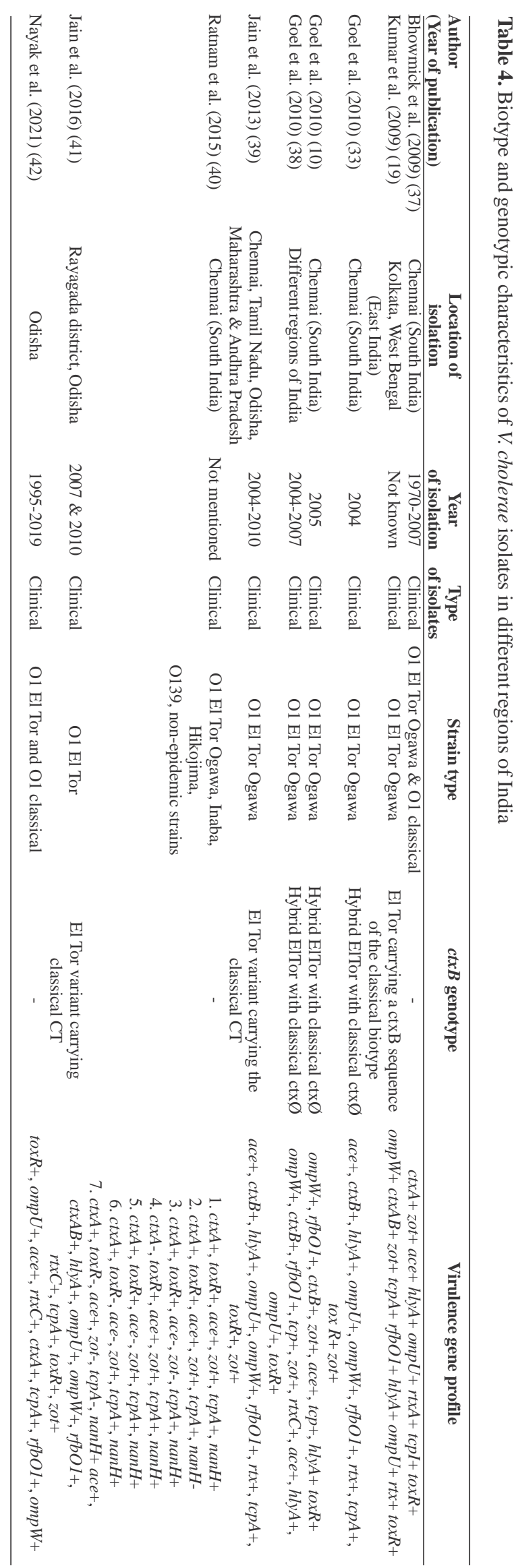

In conclusion, this study showed circulation of multidrug resistant toxigenic Vibrio cholerae O1strains in Assam carrying a large pool of virulence genes. This study also revealed that the virulence gene profile of the $V$. cholerae isolates in Assam are diverse. The major limitation of this study was the small study population. Hence, further studies should focus on the analysis of the virulence profile of large numbers of epidemic, endemic and environmental strains of $V$. cholerae in Assam to find out the clonal origin of the $V$. cholerae strains of Assam and to monitor emergence of any new virulent strain.

\section{ACKNOWLEDGEMENTS}

We gratefully acknowledge the Indian Council of Medical Research (ICMR), New Delhi for their financial support in this research work under the North East Seed Grant Scheme vide sanction no. 5/7/843/2012-RCH dated 04.09.2012.

We also express my gratitude to the National Institute of Cholera and Enteric Disease (NICED), Kolkata, West Bengal, India for providing $V$. cholerae reference strains for the study.

\section{REFERENCES}

1. Ali M, Nelson AR, Lopez AL, Sack DA. Updated global burden of cholera in endemic countries. PLoS Negl Trop Dis 2015; 9(6): e0003832.

2. World Health Organization (2014). Cholera surveillance and number of cases. World Health Organization. Geneva.

3. Siriphap A, Leekitcharoenphon P, Kaas RS, Theethakaew C, Aarestrup FM, Sutheinkul O, et al. Characterization and genetic variation of Vibrio cholerae isolated from clinical and environmental sources in Thailand. PLoS One 2017;12(1): e0169324.

4. Chatterjee SN, Chaudhuri K. Lipopolysaccharides of Vibrio cholerae. I. physical and chemical characterization. Biochim Biophys Acta 2003; 1639:65-79.

5. Garg P, Nandy RK, Chaudhury P, Roy Chowdhury NR, De K, Ramamurthy T, et al. Emergence of Vibrio cholerae O1 biotype El Tor serotype Inaba from the prevailing O1 Ogawa serotype strains in India. J Clin Microbiol 2000; 38:4249-4253.

6. Bhandari M, Jennison AV, Rathnayake IU, Huygens F. Evolution, distribution and genetics of atypical Vibrio cholerae - a review. Infect Genet Evol 2021; 89:104726.

7. Mishra A, Taneja N, Sharma RK, Kumar R, Sharma 
NC, Sharma M. Amplified fragment length polymorphism of clinical and environmental Vibrio cholerae from a freshwater environment in a cholera-endemic area, India. BMC Infect Dis 2011; 11:249.

8. Kumar P, Peter WA, Thomas S. Detection of virulence genes in Vibrio cholerae isolated from aquatic environment in Kerala, southern India. Appl Biochem Biotechnol 2008; 151:256-262.

9. Nandi B, Nandy RK, Mukhopadhyay S, Nair GB, Shimada T, Ghose AC. Rapid method for species-specific identification of Vibrio cholerae using primers targeted to the gene of outer membrane protein OmpW. J Clin Microbiol 2000; 38:4145-4151.

10. Goel AK, Jiang SC. Association of heavy rainfall on genotypic diversity in $V$. cholerae isolates from an outbreak in India. Int J Microbiol 2011; 2011:230597.

11. Koelle K, Pascual M, Yunus M. Pathogen adaptation to seasonal forcing and climate change. Proc Biol Sci 2005; 272:971-977.

12. Lü H, Yuan Y, Sun N, Bi Z, Guan B, Shao K, et al. Characterization of Vibrio cholerae isolates from 1976 to 2013 in Shandong province, China. Braz J Microbiol 2017; 48:173-179.

13. Chowdhury FR, Nur Z, Hassan N, von Seidlein L, Dunachie S. Pandemics, pathogenicity and changing molecular epidemiology of cholera in the era of global warming. Ann Clin Microbiol Antimicrob 2017; 16:10.

14. Sharma A, Sarmah Dutta B, Rasul ES, Barkataki D, Saikia A, Hazarika NK. Prevalence of Vibrio cholerae O1 serogroup in Assam, India: a hospital-based study. Indian J Med Res 2017; 146:401-408.

15. Old DG (2006). Vibrio, Aeromonas, Plesiomonas, Campylobacter, Arcobacter, Helicobacter, Wolinella. In: Mackie and McCartney Practical Medical Microbiology. Ed, Collee JG, Fraser AG, Marmion BP, Simmons A. Churchill Livingstone, 14th ed. New Delhi, pp.425-448.

16. Perilla MJ, Ajello G, Bopp C, Elliott J, Facklam R, Knapp JS, et al. Manual for the laboratory identification and antimicrobial susceptibility testing of bacterial pathogens of public health importance in the developing world. World Health Organization 2003.

17. Goel AK, Ponmariappan S, Kamboj DV, Singh L. Single multiplex polymerase chain reaction for environmental surveillance of toxigenic-pathogenic O1 and non-O1 Vibrio cholerae. Folia Microbiol (Praha) 2007; 52:81-85.

18. Keasler SP, Hall RH. Detecting and biotyping Vibrio cholerae $\mathrm{O} 1$ with multiplex polymerase chain reaction. Lancet 1993; 341:1661.

19. Kumar P, Jain M, Goel AK, Bhadauria S, Sharma SK, Kamboj DV, et al. A large cholera outbreak due to a new cholera toxin variant of the Vibrio cholerae $\mathrm{O} 1 \mathrm{El}$ Tor biotype in Orissa, eastern India. J Med Microbiol
2009; 58:234-238.

20. Chow KH, Ng TK, Yuen KY, Yam WC. Detection of RTX toxin gene in Vibrio cholerae by PCR. J Clin Microbiol 2001; 39:2594-2597.

21. Singh DV, Matte MH, Matte GR, Jiang S, Sabeena F, Shukla BN, et al. Molecular analysis of Vibrio cholerae O1, O139, non-O1, and non-O139 strains: clonal relationships between clinical and environmental isolates. Appl Environ Microbiol 2001; 67:910-921.

22. Hochhut B, Lotfi Y, Mazel D, Faruque SM, Woodgate $\mathrm{R}$, Waldor MK. Molecular analysis of antibiotic resistance gene clusters in Vibrio cholerae $\mathrm{O} 139$ and O1 SXT constins. Antimicrob Agents Chemother 2001; 45:2991-3000.

23. Falbo V, Carattoli A, Tosini F, Pezzella C, Dionisi AM, Luzzi I. Antibiotic resistance conferred by a conjugative plasmid and a class I integron in Vibrio cholerae $\mathrm{O} 1 \mathrm{El}$ Tor strains isolated in Albania and Italy. Antimicrob Agents Chemother 1999; 43: 693-696.

24. Ramachandran D, Bhanumathi R, Singh DV. Multiplex PCR for detection of antibiotic resistance genes and the SXT element: application in the characterization of Vibrio cholerae. J Med Microbiol 2007; 56:346-351.

25. Bhanumathi R, Sabeena F, Isac SR, Shukla BN, Singh DV. Molecular characterization of Vibrio cholerae O139 bengal isolated from water and the aquatic plant Eichhornia crassipes in the river Ganga, Varanasi, India. Appl Environ Microbiol 2003; 69:2389-2394.

26. Das B, Bischerour J, Barre FX. Molecular mechanism of acquisition of the cholera toxin genes. Indian J Med Res 2011; 133:195-200.

27. Abana D, Gyamfi E, Dogbe M, Opoku G, Opare D, Boateng $\mathrm{G}$, et al. Investigating the virulence genes and antibiotic susceptibility patterns of Vibrio cholerae $\mathrm{O} 1$ in environmental and clinical isolates in Accra, Ghana. BMC Infect Dis 2019; 19:76.

28. Alishahi A, Imani Fooladi AA, Fallah Mehrabadi J, Mahmoodzadeh Hosseini H. Facile and rapid detection of Vibrio cholerae by multiplex PCR based on ompU, ctxA, and toxR genes. Jundishapur J Microbiol 2013; 6(10): e7933.

29. Zaw MT, Emran NA, Ibrahim MY, Suleiman M, Awang Mohd TA, Yusuff AS, et al. Genetic diversity of toxigenic Vibrio cholerae O1 from Sabah, Malaysia 2015. J Microbiol Immunol Infect 2019; 52:563-570.

30. Akoachere JF, Mbuntcha CK. Water sources as reservoirs of Vibrio cholerae $\mathrm{O} 1$ and non-O1 strains in Bepanda, Douala (Cameroon): relationship between isolation and physicochemical factors. BMC Infect Dis 2014; 14:421.

31. Borkakoty B, Biswas D, Devi U, Yadav K, Mahanta J. Emergence of classical ctxB genotype 1 and tetracycline resistant strains of Vibrio cholerae O1 El Tor in Assam, India. Trans R Soc Trop Med Hyg 2012; 
106:382-386

32. Chatterjee S, Patra T, Ghosh K, Raychoudhuri A, Pazhani GP, Das M, et al. Vibrio cholerae O1 clinical strains isolated in 1992 in Kolkata with progenitor traits of the 2004 Mozambique variant. J Med Microbiol 2009; 58:239-247.

33. Goel AK, Jain M, Kumar P, Jiang SC. Molecular characterization of Vibrio cholerae outbreak strains with altered El Tor biotype from southern India. World $J$ Microbiol Biotechnol 2010; 26:281-287.

34. Faruque AS, Alam K, Malek MA, Khan MGQ, Ahmed $\mathrm{S}$, Saha D, et al. Emergence of multidrug-resistant strain of Vibrio cholerae $\mathrm{O} 1$ in Bangladesh and reversal of their susceptibility to tetracycline after two years. $J$ Health Popul Nutr 2007; 25:241-243.

35. Garg P, Sinha S, Chakraborty R, Bhattacharya SK, Nair GB, Ramamurthy T, et al. Emergence of fluoroquinolone-resistant strains of Vibrio cholerae $\mathrm{O} 1$ biotype El Tor among hospitalized patients with cholera in Calcutta, India. Antimicrob Agents Chemother 2001; 45:1605-1606.

36. Krishna BV, Patil AB, Chandrasekhar MR. Fluoroquinolone-resistant Vibrio cholerae isolated during a cholera outbreak in India. Trans $R$ Soc Trop Med Hyg 2006; 100:224-226.
37. Bhowmick TS, Das M, Ruppitsch W, Stoeger A, Pietzka AT, Allerberger F, et al. Detection of virulence-associated and regulatory protein genes in association with phage typing of human Vibrio cholerae from several geographical regions of the world. $J$ Med Microbiol 2009; 58:1160-1167.

38. Goel AK, Jiang SC. Genetic determinants of virulence, antibiogram and altered biotype among the Vibrio cholerae $\mathrm{O} 1$ isolates from different cholera outbreaks in India. Infect Genet Evol 2010; 10:815-819.

39. Jain M, Kushwah KS, Kumar P, Goel AK. Molecular characterization of Vibrio cholerae $\mathrm{O} 1$ reveals continuous evolution of its new variants in India. Indian $J$ Microbiol 2013; 53:137-141.

40. Ratnam PV, Sundararaj T, Rajkumar S, Anand A, Banu S. Genotyping of Vibrio cholerae strains based on the cholera toxin and virulence associated genes. Indian $J$ Appl Res 2015; 5:525-528.

41. Jain M, Kumar P, Goel AK. Emergence of tetracycline resistant Vibrio cholerae O1 biotype El Tor serotype Ogawa with classical ctxB gene from a cholera outbreak in Odisha, eastern India. J Pathog 2016; 2016:1695410.

42. Nayak AK, Nayak SR, Behera DR, Pal BB. Dissemination of Vibrio cholerae $\mathrm{O} 1$ isolated from Odisha, India. Environ Microbiol Rep 2021; 13:355-363. 